\title{
CAROTID BODY TUMOR: A CASE REPORT AND LITERATURE REVIEW
}

Rajesh Ku. Padhy ${ }^{1}$, Bijoy Kumar Dash² ${ }^{2}$ Abhishek Maheshwari ${ }^{3}$, Samir Golder ${ }^{4}$, Amrit Anand ${ }^{5}$

\section{HOW TO CITE THIS ARTICLE:}

Rajesh Ku. Padhy, Bijoy Kumar Dash, Abhishek Maheshwari, Samir Golder, Amrit Anand. "Carotid Body Tumor: A Case Report and Literature Review". Journal of Evolution of Medical and Dental Sciences 2014; Vol. 3, Issue 62, November 17; Page: 13769-13773, DOI: $10.14260 /$ jemds/2014/3840

ABSTRACT: Carotid body tumors (CBT), are rare neoplasms arising from the chemoreceptor cells of the carotid bulb. We report a case of CBT in a 41 year old female, who presented with a painless, pulsatile, gradually progressive lateral neck swelling. Diagnosis was suspected on the basis of history, clinical and radiological examination findings and a successful surgical excision of the tumor was performed. Histopathological examination confirmed the diagnosis of CBT. We also present a brief literature about CBT in terms of its clinical presentation, evaluation and management.

KEYWORDS: Carotid body tumor (CBT), carotid bifurcation, paraganglioma, Doppler.

INTRODUCTION: Carotid body was first described by von Haller in 1743. It develops from $3^{\text {rd }}$ branchial arch and also receives contribution from the neural crest. ${ }^{1}$ It is situated at the posteromedial aspect of common carotid bifurcation, embedded within its advential layer. ${ }^{2}$ It is a reddish brown to tan ovoid structure that weighs around $12 \mathrm{mg}$ in a normal adult and measure 3 to 5 $\mathrm{mm}$ in diameter. ${ }^{1}$ It is innervated by Herrings nerve, a branch of glossopharyngeal nerve. Blood flow is mainly from the external carotid artery, but can also be supplied from the vertebral artey. ${ }^{2}$

Carotid body tumor (CBT), first described by von Luschka, 1862 is a rare lesion of the neuroendocrine system. It is also known as paraganglioma, chemodectoma or glomus tumor. Approximately $5 \%$ to $7 \%$ of CBTs are malignant and $35 \%$ are hereditary. ${ }^{1}$

They present as slow growing, painless, asymptomatic lateral neck masses. The mass is firm rubbery, pulsatile and is mobile from side to side but not up and down, and can sometimes be emptied by firm pressure after which it will slowly refill in a pulsatile manner. A bruit may also be present. $^{3}$

CASE REPORT: A 41 year old female patient presented with a painless left upper neck swelling of 8 months duration. It was insidious in onset and gradually progressive. On examination, a $6 \mathrm{~cm} \mathrm{x} 4 \mathrm{~cm}$ firm non tender, pulsatile globular swelling was palpable in left upper neck (figure 1). There was a palpable thrill, and auscultation a bruit was heard. Overlying skin was normal with no local rise of temperature. The swelling was non-compressible and non-trans illuminant. It was mobile from side to side but fixed in vertical plane.

Ultrasonography of neck revealed a well-defined highly vascular mass at the bifurcation of left carotid artery. The mass had caused splaying of internal carotid artery and external carotid artery. Internal jugular vein was pushed laterally and compressed.

A contrast enhanced CT scan of neck revealed a $6.5 \mathrm{~cm} \times 4.3 \mathrm{~cm} \times 3.6 \mathrm{~cm}$ well circumscribed highly enhancing homogenous soft tissue mass lesion. There was splaying of ICA and ECA with compression and lateral displacement of IJV (figure 2). There was no cervical lymphadenopathy. 24 hour urine vanillil mandelic acid (VMA) and catecholamine was within normal limits. 
Considering the clinical and radiological features, a diagnosis of CBT was rendered and patient was taken up for surgery. Using a left transcervical approach, the mass was exposed and dissected from its attachment at the carotid bifurcation and removed (Figure 3). The lower cranial nerves were normal. Histopathological examination of resected specimen was reported as carotid body paraganglioma. Postoperative period was uneventful. During a follow up period of one and a half years patient was asymptomatic and there was no clinical evidence of recurrence.

DISCUSSION: CBT is the most common paraganglioma of the head and neck region and represent about $3 \%$ of the whole body paraganglioma's. ${ }^{2}$ They most commonly present in the $5^{\text {th }}$ decade. Majority of these originate in the inter-carotid paraganglia. Chronic hypoxia leading to carotid body hyperplasia in people dwelling at higher altitudes is a well-recognized causative factor. In familial paraganglioma's, the most common inherited genetic abnormality is the mutation in the D subunit of the succinate dehydrogenase gene. ${ }^{2}$

Clinically patients often present with a slowly enlarging painless lump in the upper lateral neck. On examination the mass is firm, non-tender, rubbery and is freely mobile sideways but limited in craniocaudal direction (Fontaine's sign). ${ }^{2}$ About one third present with a pharayngeal mass pushing the tonsil medially and anteriorly. ${ }^{3}$ A carotid bruit may also be present, which together with the pulsatile nature of the lump raises the suspicion of a CBT. With increase in size of the CBT, there develops dysphagia, hoarseness and features of cranial nerve (IX - XII) deficits and sympathetic chain involvement. ${ }^{4}$

Other lateral cervical masses that confuse the diagnosis of CBT are cervical lymphadenopathy, carotid aneurysms, branchial cleft cysts, salivary gland tumors, neurogenic tumors. ${ }^{5}$ About $1 \%-3 \%$ of head and neck paraganglioma present as functional neuropeptide secreting tumor. Bilateral CBT is the most common pattern of multiple paraganglioma's in the head and neck region. ${ }^{2}$

Microscopically paragangliomas consists of well differentiated neuroendocrine cells in small clusters (Zellballen) or cords separated by prominent fibrovascular stroma. Cells have dark neurosecretory granules that contain catecholamines. Paragangliomas originating below the neck region usually manifest early because of catecholamine production.6Paraganglioma's are mostly benign but as much as 5 to $7 \%$ are malignant. Local invasion and distant metastasis are the determinants of malignant potential of paragangliomas. ${ }^{7}$

Radiological evaluation is imperative in establishing the diagnosis and treatment planning. In B-Mode sonography CBT's appear as solid, well defined hypoechoic masses. Characteristically there is a splaying of carotid bi furcation; both ICA and IJV are displaced posteriorly while ECA is usually pushed anteriorly. The diagnostic accuracy is increased with the addition of colour coded Doppler which shows CBT's as hypervascular masses and majority of intratumoral flow signal is directed upwards. ${ }^{8}$

In a contrast enhanced CT scan CBT's show accumulation with widening of carotid bifurcation. In a Magnetic resonance imaging CBT's exhibit low signal intensity on T1 weighted images and high signal intensity on T2 weighted images. The characteristic 'Salt and Pepper appearance' of the tumor representing areas of high and low signal intensity is because of the high and low blood flow within the tumor mass. ${ }^{9-10}$ Digital subtraction angiography is the gold standard for detection of small paragangliomas. 
Carotid paragangliomas has been classified by Shamblin et al. into 3 groups: group I - small tumors easily separated from the carotid vessels; group II - medium sized tumors that are intimately adherent to the vessels and may be separated from them by sub-adventitial dissection; group III large tumors that encase the ICA at the bifurcation and often require a partial or complete sacrifice of the vessel with replacement. ${ }^{11}$

Various types of surgical procedures for CBT's ranging from simple excision to sub adventitial tumor excision with or without vascular reconstruction has been described by various authors. ${ }^{12}$ Vascular reconstruction with end to end anastomosis or using saphenous interposition vein graft, polytetrafluroethylene (PTFE) 6mm graft, Dacron $8 \mathrm{~mm}$ graft has been described.

With the improvement in surgical skills, CBT surgery has become relatively safe with reduced incidence of major cerebrovascular complications. Rate of complication is higher if tumor size exceeds $4 \mathrm{~cm} \cdot{ }^{13}$ Serious postoperative hypertension can result following excision of bilateral CBT's. This is because of failure of baroreceptor arc reflex. ${ }^{14}$

CONCLUSION: Any painless gradually progressive upper lateral neck swelling should be scrutinized carefully by keeping CBT as a differential diagnosis in mind. Doppler sonography and contrast enhanced CT scan has revolutionized the diagnosis of CBT's. With advancement in vascular reconstruction techniques and planned surgical excision of tumor, the surgical complications have been reduced to a considerable extent.

\section{REFERENCES:}

1. Lin PH, Kougias P, Bechara C, Cagiannos C, Huynh TT, Chen CJ. Arterial disease. In: Brunicardi FC et al., editors. Schwartz's principles of surgery. 9th ed. New York: The McGraw-Hill companies; 2010. pp. 721-23.

2. Day TA, Buchmann L, Rumboldt Z, Joe JK. Neoplasms of the neck. In: Flint PW, Haughey BH, Lund VJ, Niparko JK, Richardson MA, Robbins KT et al, editors. Cumming's Otolaryngology, head \& neck surgery. 5th ed. vol 2. Philadelphia; Mosby Elsevier publications, 2010; 1657-1661.

3. Pharrnx, larynx and neck. In: Russell RCG, Williams NS, Bulstrode CJK, editors. Bailey and love's short practice of surgery. 24th ed. London; Hodder Arnold, 2004; 774-75.

4. Patetsios P, Gable DR, Garrett WV. Management of carotid body paragangliomas and review of a 30-year experience. Ann Vasc Surg 2002; 16: 331-38.

5. Stoeckli SJ, Schuknecht B, Alkadhi H. Evaluation of paragangliomas presenting as a cervical mass on color-coded doppler sonography. Laryngoscope 2002; 112: 143-46.

6. Neumann HP, Bausch B, McWhinney SR, Bender BU, Gimm O, Franke G. Germ-line mutations in nonsyndromic pheochromocytoma. N Engl J Med 2002; 346: 1459-66.

7. Somasundar P, Krouse R, Hostetter R, Vaughan R, Covey T. Paragangliomas - A decade of clinical experience. J Surg Onco 2000; 74: 286-90.

8. Carroll W, Stenson K, Stringer S. Malignant carotid body tumour. Head Neck 2004; 26: 301-06.

9. Olsen WL, Dillion WP, Kelly WM, Norman D, Brant-Zawadzki M, Newton TH. MR imaging of paragangliomas. Am J Roentgenol 1987; 148 (1): 201-04.

10. Van den Berg R, Verbist BM, Mertens BJA, van der Mey AGL, Van Buchem MA. Head and neck paragangliomas: improved tumor detection using contrast-enhanced 3D time-of flight MR angiography as compared with fat-suppressed MR imaging techniques. Am J Neuroradiol 2004; 25 (5): 863-70. 


\section{CASE REPORT}

11. Shamblin WR, Re Mine WH, Sheps SG. Carotid body tumour: clinicopathologic analysis of ninety cases. Am J Surg 1971; 122: 732-739.

12. Davidovic L, Ilic N, Dimitrijevic M, Dukic V, Dzodic R. Surgical management of cervical paragangliomas. The Am Surg Dec 2008; 74 (12): 1171-76.

13. Makeieff M, Raingeard I, Alric P, Bonafe A, Guerrier B, Marty-Anne C. Surgical management of carotid body tumours. Ann Surg Oncol 2008; 15 (8): 2180-86.

14. De Toma G, Nicolanti V, Plocco M. Baroreflex failure syndrome after bilateral excision of carotid body tumors: an underestimated problem. J Vasc Surg 2000; 31: 806-10.

FIGURE 1: Patient photograph showing the upper lateral neck swelling due to Left Carotid Body Tumor.

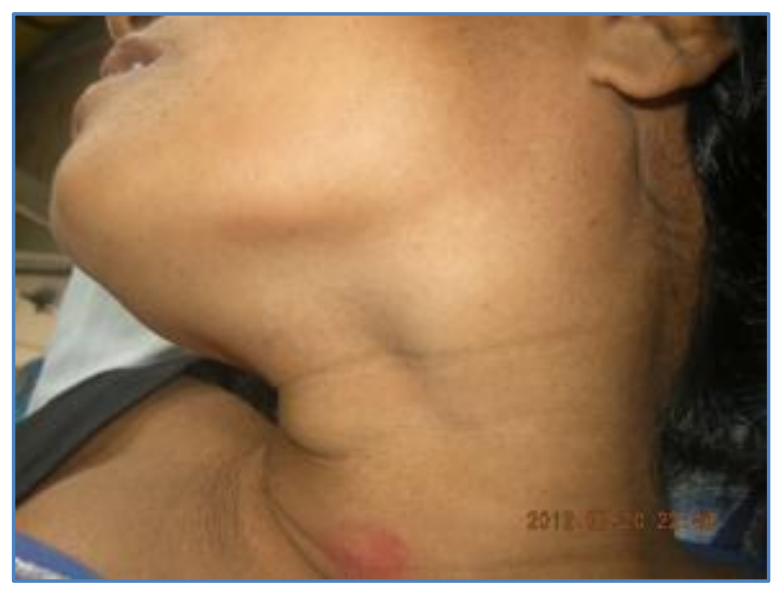

Figure 1

FIGURE 2: CT Scan - Axial View showing contrast enhancing mass pushing left carotid artery anteriorly and compressing left internal jugular vein laterally.

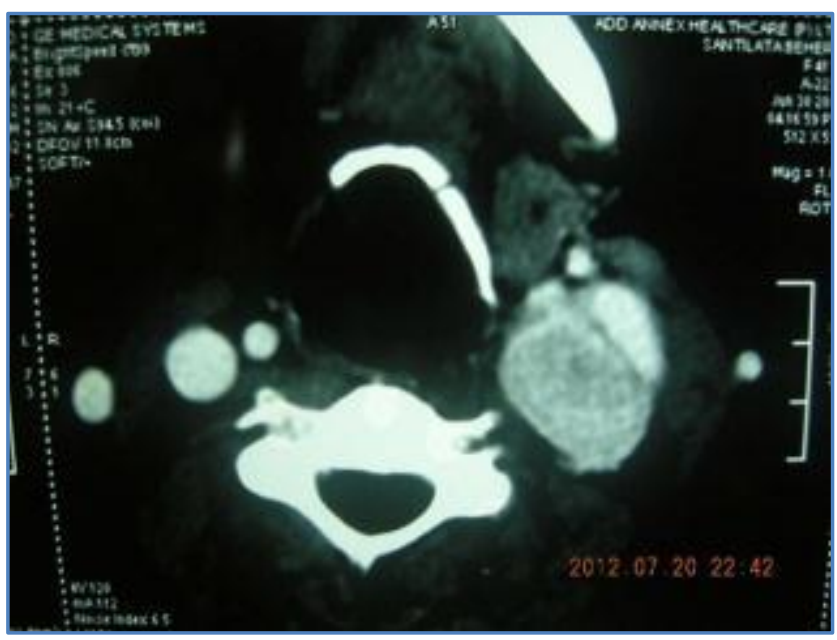

Figure 2 


\section{CASE REPORT}

FIGURE 3: Left Carotid body tumour dissected from its attachment at the carotid bifurcation and removed in toto.

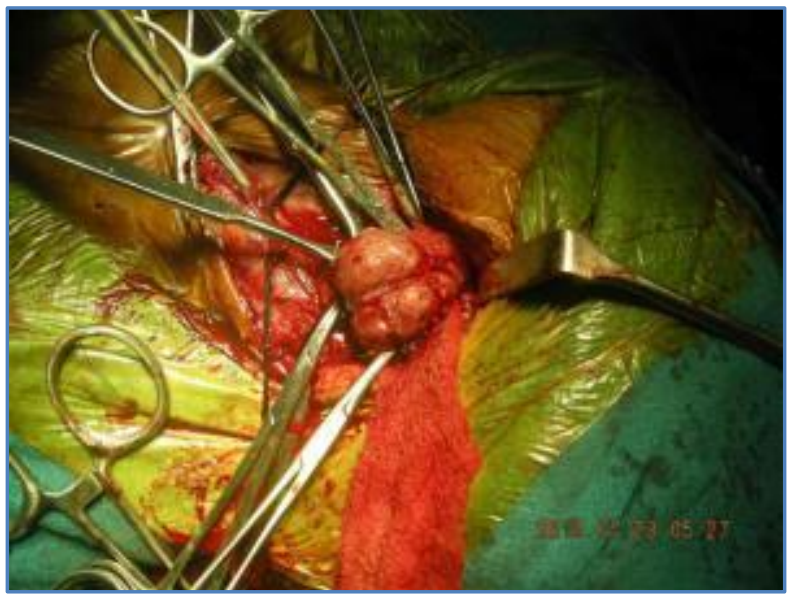

Figure 3

\section{AUTHORS:}

1. Rajesh Ku. Padhy

2. Bijoy Kumar Dash

3. Abhishek Maheshwari

4. Samir Golder

5. Amrit Anand

\section{PARTICULARS OF CONTRIBUTORS:}

1. Associate Professor, Department of ENT, Hi-Tech Medical College and Hospital, Bhubaneswar, Odisha.

2. Professor, Department of ENT, Hi-Tech Medical College and Hospital, Bhubaneswar, Odisha.

3. Post Graduate Student, Hi-Tech Medical College and Hospital, Bhubaneswar, Odisha.

4. Post Graduate Student, Hi-Tech Medical College and Hospital, Bhubaneswar, Odisha.
5. Post Graduate Student, Hi-Tech Medical College and Hospital, Bhubaneswar, Odisha.

\section{NAME ADDRESS EMAIL ID OF THE CORRESPONDING AUTHOR:}

Dr. Rajesh Ku. Padhy, Associate Professor, Department of ENT, Hi-Tech MCH, BBSR.

Email: dr.rajeshkumarpadhy@gmail.com

Date of Submission: 29/10/2014.

Date of Peer Review: 30/10/2014.

Date of Acceptance: 12/11/2014.

Date of Publishing: 17/11/2014. 